\title{
El derecho a la educación de las mujeres como derecho clave hacia una cultura de Igualdad
}

\author{
La educación es un poder para las mujeres, \\ y eso es por lo que los terroristas le tienen \\ miedo a la educación. Ellos no quieren que \\ una mujer se eduque porque entonces esa \\ mujer será más poderosa. \\ Malala Yousafzal ${ }^{1}$
}

Yarib Hernández García ${ }^{2}$

Encargada de la Defensoría de los Derechos Universitarios Universidad Autónoma Benito Juárez de Oaxaca ${ }^{3}$

\begin{abstract}
A lo largo de la historia, las mujeres hemos ido ganado espacios. Aun cuando se ha logrado la inclusión de las mujeres en lo humano, ha implicado trastocar la concepción de la humanidad y la experiencia histórica misma y, en ese sentido, los avances son insuficientes. La concepción sobre derechos humanos, no ha logrado instalarse del todo en la cultura, ni como mentalidad ni como práctica. El derecho a la educación es un derecho clave, pues nos permite acceder a otros derechos que resultan indispensables para una vida en dignidad. A pesar de lo anterior, en nuestros días aún existen brechas para poder acceder a una educación en igualdad de circunstancias.
\end{abstract}

Activista Pakistani, Premio Nobel de la Paz en 2014.

2 Licenciada en Derecho, con estudios de Maestría en Derechos Humanos por la Universidad Autónoma Benito Juárez de Oaxaca. Especialista en Derechos de Infancia y Adolescencia. Correo electrónico: yaribhg@gmail.com

3 Edificio A de Rectoría, primer nivel. Av. Universidad s/n, Colonia Cinco Señores. Oaxaca de Juárez, Oaxaca. 


\section{Antecedentes}

Los primeros documentos internacionales en reconocer lo que ahora conocemos como Derechos Humanos, fueron la Declaración de Derechos de Virginia, del año 1776, en la cual se instituyeron como "Derechos inherentes a todas las personas"; y la Declaración de los Derechos del Hombre y del Ciudadano de 1789, en donde se reconocieron como derechos naturales, inalienables y sagrados del hombre. Si bien estos documentos marcan el inicio del reconocimiento de derechos, garantizaban únicamente aquellos que correspondían a las personas del sexo masculino. Por tal razón, generaron la inconformidad de mujeres y fue hasta 1843 que se redactó la "Declaración de los Sentimientos" la cual proclamaba que: "todos los hombres y las mujeres" fueron creados iguales y que se emplearía todos los métodos que estuvieran a su disposición para combatir estas injusticias (Beltrán, Maquieira, Álvarez, Sánchez, 2008). En ese contexto surgió el feminismo histórico, que fue el primer movimiento en buscar el rompimiento de los estereotipos, reivindicando la igualdad de oportunidades y derechos para las mujeres. Estos antecedentes relativos a los derechos de las mujeres en situaciones específicas son medidas para hacer un contrapeso a la desigualdad.

Los cambios filosóficos, éticos y políticos son trascendentes para concebir la categoría de los derechos humanos. El plural expresa la incorporación de las mujeres como género en lo humano y, al mismo tiempo, los hombres -contenido implícito del simbólico el hombre-, dejan de representar a la humanidad (Lagarde y De los Ríos, 1996). México, ha reforzado su compromiso en materia de cumplimiento de los Derechos Humanos desde la reforma constitucional de 2011. En ella se logró el reconocimiento expreso de los Derechos Humanos y establece la obligación del propio Estado, a través de todas las autoridades en el ámbito de sus competencias de promover, respetar, proteger y garantizar dichos derechos, de conformidad con los principios de universalidad, interdependencia, indivisibilidad y progresividad. En el ámbito nacional, la Ley General de Acceso de las Mujeres a una Vida Libre de Violencia (LGAMVLV), es el documento que reglamenta la obligatoriedad del Estado mexicano y sus entidades federativas a establecer acciones para prevenir, sancionar y erradicar la violencia contra las mujeres; así como los principios y modalidades para garantizar su acceso a una vida libre de violencia, que favorezca su desarrollo y bienestar conforme a los principios de igualdad y de no discriminación. 


\section{Derecho de las mujeres a la educación, como derecho clave hacia una cultura de igualdad}

Cualquier persona es titular de los derechos establecidos en la Constitución, los tratados en la materia ratificados por el Estado mexicano y la legislación aplicable. Adicionalmente, las Convenciones CEDAW ${ }^{4}$ y Belém do Pará, ${ }^{5}$ la LGAMVLV y las legislaciones locales y especializadas, refuerzan los derechos de las niñas y mujeres y plantean otros adicionales que deben ser respetados y garantizados por todas las instituciones del Estado mexicano, ${ }^{6}$ dentro de los que se encuentran el derecho a la educación. ${ }^{7}$

Los derechos humanos de las mujeres abarcan todos los aspectos de la vida, que son: a la propia vida, a la salud, derechos sexuales y reproductivos, a la participación política, al trabajo, a la información, acceso a la justicia y, el derecho a ser libre de todas las formas de discriminación contra la mujer para lograr una igualdad efectiva. Otro derecho es el de prevenir, sancionary erradicar la violencia contra las mujeres. Acerca de estos derechos debemos realizar una profunda reflexión porque más allá del abordaje judicial, la violencia contra las mujeres es un fenómeno con profundo contenido histórico, vinculado con comportamientos sociales y culturales.

Las posibilidades de participar con igualdad en los ámbitos educativo, laboral, político, religioso y social, nos permiten lograr una plena autonomía. Es importante entender que igualdad no significa dar el mismo trato a hombres y mujeres. Por el contrario, debe reconocerse la existencia de condiciones e incluso de cuerpos diferentes, con necesidades distintas, para darles un trato especial a las mujeres y a los hombres.

El ejercicio del derecho a la educación de las mujeres es un derecho clave hacia una cultura de igualdad. Una mujer preparada es capaz de lograr una autonomía económica, que le da la pauta a otros tipos de independencia y empoderamiento para la toma de decisiones, tales como el libre ejercicio de la ciudadanía, la participación política y el pleno acceso al goce de los derechos humanos. Por ello, es menester que la mujer tenga acceso a condiciones

4 La Convención está redactada en términos de obligaciones de los Estados, algunas de las cuales son programáticas y/o generales, pero otras se refieren a derechos concretos, como: participación y derechos políticos (art. 7), a vivir libre de explotación y prostitución (art. 6), representación de gobiernos (art. 8), nacionalidad (art. 9), educación (art. 10), empleo (art. 11), salud (art. 12), derechos económicos (art. 13), igualdad ante la ley (art. 15) e igualdad en el matrimonio y las relaciones familiares (art. 16).

5 Cfr. Artículos 3, 4 y 5. Adicionalmente, en lo tocante a las obligaciones de los Estados, ver principalmente los a artículos 7 y 8 del mismo tratado.

6 La Corte Interamericana ha señalado establecido que "en casos de violencia contra la mujer, los Estados tienen, además de las obligaciones genéricas contenidas en la Convención Americana, una obligación reforzada a partir de la Convención Belém do Pará." Corte IDH. Caso Campo algodonero, Op. Cit., párr. 258

7 "Toda mujer tiene derecho a ejercer libremente sus derechos.". Cfr., artículo 5, Convención de Belém do Pará 
adecuadas para la permanencia en la educación formal y, especialmente una educación libre de estereotipos, sesgos y discriminación, con el fin que conozca sus derechos y sea capaz de exigirlos. También, para que tenga una preparación adecuada para enfrentarse al mundo laboral y no dependa de otras personas para hacerse escuchar y darse a respetar.

En la Declaración Universal de los Derechos Humanos se estableció que el objetivo de la educación es el pleno desarrollo de la personalidad humana y el fortalecimiento del respeto a los derechos humanos y a las libertades fundamentales ${ }^{8}$. En palabras del Comité de Derechos Económicos Sociales y Culturales', la educación es un derecho humano intrínseco y un medio indispensable para realizar otros derechos humanos, como derecho del ámbito de la autonomía de la persona, la educación es el principal medio que permite salir de la pobreza y participar plenamente. La educación desempeña un papel decisivo en la emancipación de las mujeres, la protección de la infancia contra la explotación laboral, el trabajo peligroso y la explotación sexual, la promoción de los derechos humanos y la democracia, la protección del medio ambiente y el control del crecimiento. ${ }^{10}$

La educación al igual que los derechos humanos, le imponen tres niveles de obligaciones a los Estados: el deber de respetar, que exige a los Estados evitar las medidas que obstaculicen o impidan el disfrute del derecho a la educación; la obligación de proteger, impone a los Estados que adopten medidas para impedir que el derecho a la educación sea limitado por terceros y, la de dar cumplimiento, exige que los Estados desarrollen acciones positivas que permitan a los individuos y a las comunidades disfrutar del derecho a la educación y les presten asistencia. Además, para ejercer la educación se deben cumplir con aspectos de disponibilidad (las instituciones y programas tienen que estar disponibles en cantidad suficiente), accesibilidad (esto es, que sean accesibles para todas y todos), aceptabilidad (adecuados y de buena calidad) y adaptabilidad (que respondan a las necesidades y contextos).

8 La educación tendrá por objeto el pleno desarrollo de la personalidad humana.. ". Cfr., artículo 26.2, Declaración Universal de los Derechos Humanos.

9 El Comité de Derechos Económicos, Sociales y Culturales, se estableció en virtud de la resolución 1985/17. De 28 de mayo de 1985, del Consejo Económico y Social de las Naciones Unidas para desempeñar las funciones de supervisión del Pacto Internacional de Derechos Económicos, Sociales y Culturales.

10 Comité de Derechos Económicos, Sociales y Culturales, Observación General N 13 (1999), El derecho a la educación (art. 13) del 8 de diciembre de 1999, párr.1 La educación es un derecho humano intrínseco y un medio indispensable de realizar otros derechos humanos (...) 


\section{Conclusiones}

El derecho a la educación es un medio de cultivo óptimo para promover una cultura de respeto, observancia y pleno goce de los derechos humanos de las mujeres, como parte inalienable, integrante e indivisible de sus derechos. Debemos apostar por una reformulación global de los derechos humanos desde una perspectiva de género, ya que al no aplicarse por igual las necesidades, deseos, demandas y especificidades de las mujeres se hacen invisibles. Es nuestro deber asumir una postura definitiva y progresista, que permita diseñar, implementar y evaluar de manera inmediata una política pública que avance en la protección de los derechos de las mujeres, que incluyan de forma transversal la promoción de un entorno educacional que garantice la igualdad de oportunidades de acceso y atención a los hombres y a las mujeres. Ello desde el ámbito universitario, debido al papel central de las políticas educativas, ya que éstas repercuten en las esferas de la sociedad y permitiría cerrar brechas de desigualdad entre hombres y mujeres en el aspecto educativo.

\section{Referencias}

Beltrán E, Maquieira V, Álvarez S, Sánchez C. (2008) "Feminismos, debates teóricos contemporáneos. Recuperado de: http://www.cieg.unam.mx/lecturas_formacion/relaciones_genero/modulo_2/sesion_1/Maquieira_Feminismos_Debates_Teoricos_Contemporaneos.pdf

Lagarde y D. L. R. M. (1996). Identidad de género y derechos humanos. "La construcción de las humanas", en Estudios Básicos de Derechos Humanos IV. San José: Instituto Interamericano de Derechos Humanos. 